\title{
QUATRO NOVAS ESPÉCIES DE PSYLLOBORA CHEVROLAT, 1837 (COLEOPTERA, COCCINELLIDAE ${ }^{1}$
}

Lúcia Massutti de Almeida 2

\begin{abstract}
Four new species of Psyllobora Chevrolat, 1837/P. batesi, P. borgmeiri, P. gorhami and $\mathbf{P}$. huancayensis) from Neotropical Region are described and illustrated.
\end{abstract}

Psyllobora batesi sp. n.

(Figs. 1-4)

Diagnose : Cabeça com clípeo fundido à fronte sem linha de sutura e sem depressão. Mandíbulas de bordo externo curvo, mola com dente. Corpo arredondado, glabro com tegumento amarelado leitoso e máculas marrons. Pronoto com área central amarelada mais escura que o tegumento. Élitro com 6 máculas (Fig. 1): 3 das quais unidas, formando una grande figura que se estende desde a base elitral até pouco antes do ápice, seguindo paralelamente à sutura elitral, interrompendo-se logo na base por uma faixa oblíqua (entre a $1^{\mathrm{a}}$ e a $2^{\mathrm{a}}$ máculas), e com outra faixa que separa a $2^{\mathrm{a}}$ da $3^{\mathrm{a}}$ se prolongando até pouco mais da metade do élitro. Esta 3 . mácula cobre o calo umeral e se afina em seguida, se prolongando até se unir novamente com a parte posterior das $11^{\mathrm{a}}$ e $2^{\mathrm{a}}$. máculas. Duas outras máculas alongadas, se unem próximo ao meio do élitro, e acompanham o bordo externo, iniciando logo abaixo da altura do calo umeral e terminando pouco antes do ápice da união das três primeiras máculas. A última mácula, no ápice do élitro, oval, e isolada, acompanha o bordo externo do élitro.

Genitália. Machos: Lobo médio largo na base, estreitando-se gradativamente para o ápice; parâmeros pouco maiores que o lobo médio com cerdas longas (Fig. 2). Sifão sem projeções laterais ou apicais (Fig. 3). Fêmeas: Espermateca ramificada, na extremidade da sua curvatura subigual ao 1 o esterno abdominal visivel, infundíbulo cônico (Fig. 4).

Medidas: $3,84-4,84 \mathrm{~mm}$ de comprimento e 3,27-3,78 mm de largura.

Variações: A 1 a e $2^{\mathrm{a}}$. máculas podem estar totalmente unidas, as $1 \stackrel{\mathrm{a}}{\text {, }}, 2^{\mathrm{a}}$ e e $3^{\mathrm{a}}$ também podem estar unidas formando uma mácula única. As máculas 1 a, 2 , , 3 ?, $5^{\mathrm{a}}$ ? e $6^{\mathrm{a}}$ às vezes formam uma grande mácula onde todas as extremidades ficam fechadas e resta apenas uma figura semelhante a um losango.

1. Contribuição n. 681 do Departamento de Zoologia da UFPR

2. Pós-Graduação, doutorado, Depto. Zoologia, UFPR, Caixa Postal 19.020, 81.504, Curitiba, Paraná, Brasil. 
Revta bras. Zool.
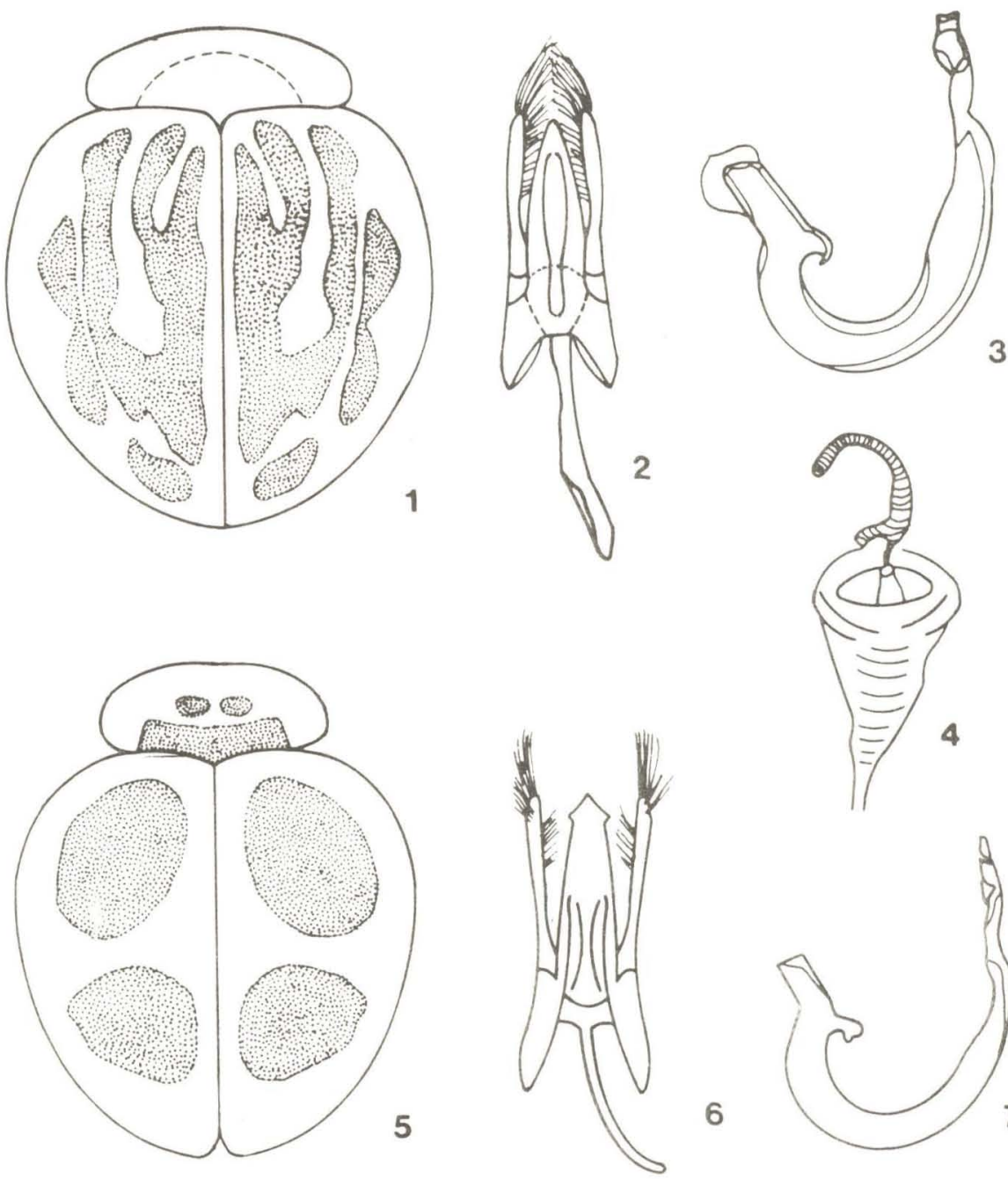

6

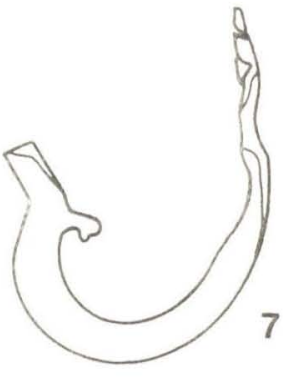

Fig. 1-7. Psyllobora batesi sp.n. 1. pronoto e élitros; 2. lobo médio; 3. sifão; 4. espermateca; Psyllobora borgmeiri sp.n.; 5 . pronoto e élitros; 6 . lobo médio; 7. sifão. 
Vol. 7(3), 1990
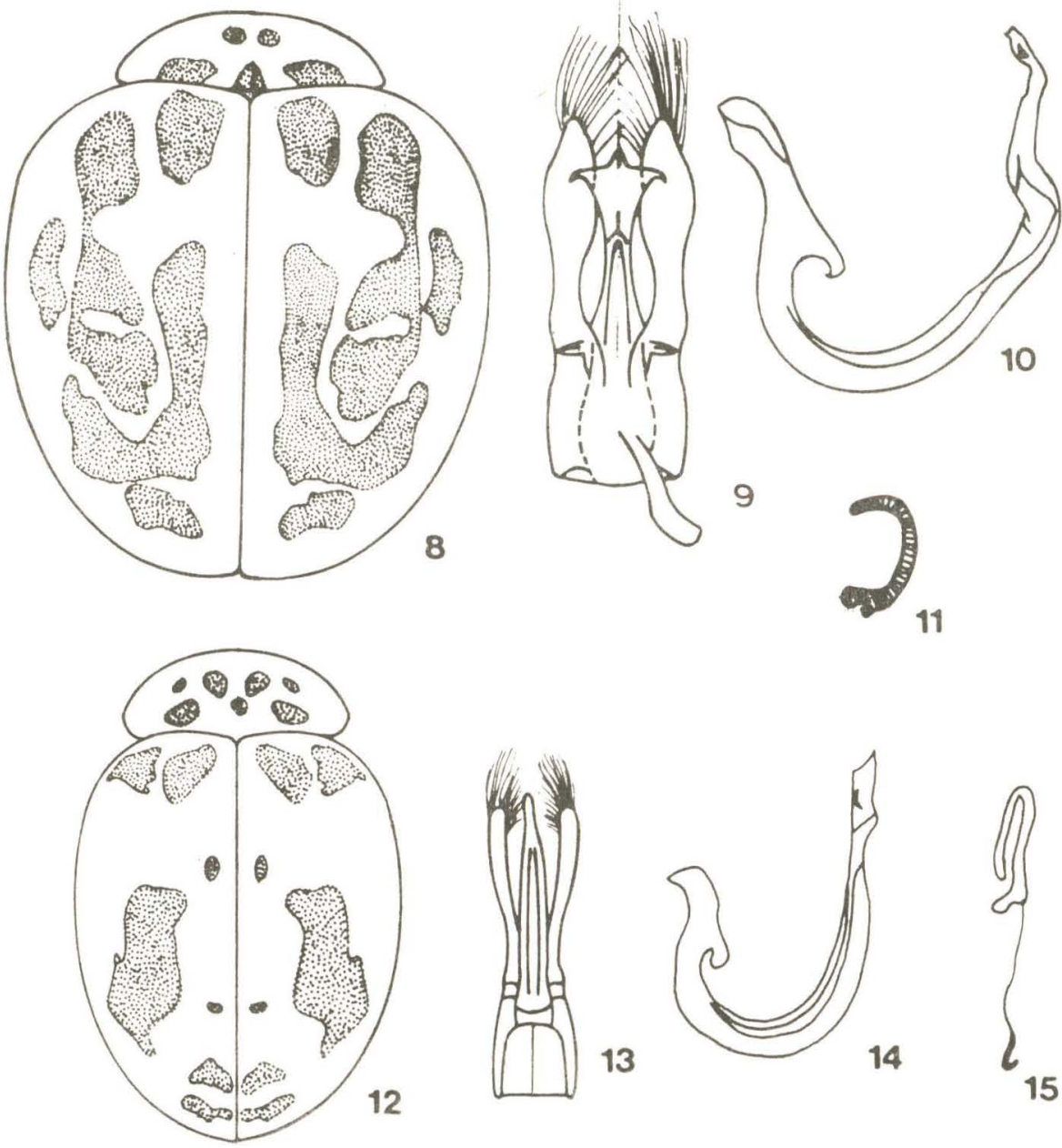

Figs. 8-15 - Psyllobora gorhami sp.n. 8. pronoto e élitros; 9. lobo médio; 10. sifāo; 11. espermateca: Psyllobora huancayensis sp.n. 12. pronoto e élitros; 13. lobo médio; 14. sifão; 15. espermateca. 
Comentários: Esta espécie é próxima de $P$. picturata porém dela difere por apresentar as máculas mais unidas entre si; por não apresentar máculas no pronoto; pela forma diferente do lobo médio que em $P$. picturata é em seta pequena; e pelo comprimento dos parâmeros que naquela espécie é menor que o lobo médio.

Material Tipo: Holótipo macho do Amazonas, Brasil, de 20/XII/1939, coletado por Balint, depositado no Museu Nacional, Rio de Janeiro. Os parátipos estão depositados no Museu Nacional do Rio de Janeiro (MNRJ) e no Departamento de Zoologia da Universidade Federal do Paraná (DZUP), conforme segue:

Brasil. Amazonas, 20/XII/1939, 23 ex. (DZUP); Pará, Marajá (Faz. Ribanceira), 8/II/1945, J. A. Camargo, 1 ex. (MNRJ e DZUP); Belterra, 79 ex. (MNRJ e DZUP).

\section{Psyllobora borgmeiri sp. $\mathrm{n}$.}

(Figs. 5-7)

Diagnose: Cabeça com clípeo fundido à fronte sem linha de sutura e sem depressão. Mandíbulas robustas com bordo externo em ângulo, mola com dente.

Corpo arredondado, glabro com tegumento amarelado leitoso com máculas marrons. Pronoto com 2 máculas apicais arredondadas e mais uma mácula basal, grande e retangular. Élitro com 2 máculas grandes, a 1a ovalada na metade anterior do élitro. A 2. também ovalada, oblíqua na metade posterior (Fig. 5).

Genitália. Machos: Lobo médio com o ápice em seta larga e parâmeros aproximadamente do mesmo tamanho do lobo médio com cerdas longas (Fig. 6). Sifão sem prolongamento no ápice (Fig. 7).

Fêmeas: Não conhecida.

Medidas: 3,17-3,33 $\mathrm{mm}$ de comprimento; 2,75-2,92 $\mathrm{mm}$ de largura.

Comentários: Esta espécie têm um padrão de máculas distinto dos demais espécies conhecidos no género por serem de contorno bem arredondado. Porém parece ser mais próxima de $P$. peruana por possuir máculas grandes ocupando boa parte do élitro e pelo padrão semelhante do lobo médio em seta larga. Porém dela difere pelo tamanho menor, pela forma mais arredondada e pelo padrão das máculas elitrais.

Material Tipo: Holótipo de Tucurrique, Costa Rica, coletado por Schild \& Burgdorf. Parátipo, 2 exemplares com os mesmos dados do holótipo. Todos os tipos estão depositados no Museu Nacional do Rio de Janeiro (MNRJ).

\section{Psyllobora gorhami sp. n.}

(Figs. 8-11)

Diagnose: Cabeça com clípeo fundido à fronte sem depressão ou linha de sutura. Mandíbulas com bordo externo curvo, mola com dente. Corpo arredondado, glabro com tegumento amarelado leitoso e máculas marrons (Fig. 8). Pronoto com 5 máculas negras: duas menores apicais, ovaladas; das 3 basais, uma menor central, triangular e 2 maiores laterais. Élitro com 5 máculas: a 1. ovalar, na base, próxima à sutura, uma 2a mácula alongada (provavelmente formada pela união de 3 máculas), dirigindo-se longitudinalmente desde o calo umeral até o segundo terço do élitro. A 3a mácula em forma de L, 
junto a sutụra, iniciando pouco abaixo da altura do calo umeral e seguindo até os três quartos do élitro onde volta para o lado do bordo externo envolvendo a parte posterior na mácula do calo. 4a mácula menor, iniciando logo abaixo da altura do calo umeral, próxima do bordo externo, última mácula apical, logo abaixo da mácula em L. Ápice de cada élitro, na face interna, com pequeno espinho como prolongamento da sutura.

Genitália. Machos: Lobo médio estreito na base, se afunilando para o meio e em seguida se alargando formando duas pontas laterais e uma apical. Parâmeros maiores que o lobo médio (Fig. 9). Sifão sem projeção (Fig. 10).

Fêmeas: Espermateca ramificada, na extremidade de sua curvatura com comprimento subigual ao 1 ? esterno abdominal visível (Fig. 11).

Medidas: 3,58 mm de comprimento; 3,33 mm de largura.

Comentários: Espécie próxima de $P$. confluens e dela difere por apresentar a 3 a mácula unida a outras duas formando um L enquanto que naquela as máculas são separadas entre si; a distância entre as duas máculas suturais é maior em $P$. confluens e ainda nesta espécie o ápice do élitro apresenta um pequeno espinho. O lobo médio de $P$. gorhami possui processos laterais bem maiores que naquela espécie.

Material Tipo: Holótipo de Turrialba, Costa Rica, lâmina 593/FCC-703, depositado no Museu Nacional do Rio de Janeiro (MNRJ).

Comentários: No material examinado, pertencente ao Museu Nacional do Rio de Janeiro, ex-coleção Felisberto C. Camargo, há apenas um exemplar macho e duas lâminas, uma delas da fêmea, cujo exemplar não foi localizado. Segundo anotações do mesmo pesquisador, a fêmea é da Guatemala e pertence ao Museu Britânico (Coleção Champion).

\section{Psyllobora huancayensis sp. n.}

(Figs. 12-15)

Diagnose: Cabeça com clípeo fundido à fronte sem depressão ou linha de sutura. Mandíbulas com bordo externo curvo, mola com dente. Corpo ovalado, glabro com tegumento amarelado leitoso, com máculas marrons (Fig. 12). Pronoto com 7 máculas: uma central arredondada, duas basais, uma de cada lado da central, mais alongadas, duas apicais mais juntas e duas entre as apicais e as basais. Élitro com 7 máculas: a 1. triangular, basal, proxima da sutura; a 2 a sobre o calo umeral; a 3 ? muito pequena, alongada, na mesma linha da 1:; a 4a a maior de todas, irregular, abrangendo de comprimento quase $1 / 3$ do élitro; a 5. muito pequena, arredondada, entre a 4. e a sutura; as 6 ? $^{\mathrm{a}}$ e 7 ? $^{\mathrm{a}}$ alongadas, apicais e transversas. Meso, metasterno e parte central dos $1^{\text {OS }}$ esterno abdominal visível negros.

Genitália: Macho. Lobo médio com ápice alongado, mamiliforme, parâmeros menores, com cerdas longas (Fig. 13). Sifão sem projeção apical (Fig. 14).

Fêmeas: Espermateca com pequena ramificação, nas extremidades de sua curvatura menor que o 1 \% esterno abdominal visível (Fig. 15).

Medidas: 2,69-3,26 mm de comprimento; 2,24-2,49 $\mathrm{mm}$ de largura. 
Comentários: Espécie próxima de $P$. plagiata, porém dela difere por possuir a mácula maior do disco elitral mais alongada; mais três máculas elitrais, uma sutural na 2 . metade elitral e duas transversais no ápice do élitro; pela forma mais alongada; e pelas máculas do pronoto em número e tamanho maior.

Material Tipo: Holótipo de Huancayo (Hotel Monterey, 2.970 m), 11-23/1/1967, Dahlia leg. (?). Parátipos, 56 exemplares. Os tipos acham-se depositados no Museu Nacional do Rio de Janeiro (MNRJ) com exceção de 20 no Departamento de Zoologia da Universidade Federal do Paraná (DZUP).

\section{REFERENCIAS}

ALMEIDA, L.M. \& MARINONI, R.C., 1983. Contribuição ao conhecimento do Gênero Psyllobora Chevrolat, 1837. (Coleoptera-Coccinellidae). Revta. Bras. Ent., 27(2):165-175.

ALMEIDA, L.M., 1987. Estudos de 17 espécies do gênero Psyllobora Chevrolat, 1837 (Coleoptera Coccinellidae). Acta. Biol. Par. 14(1, 2, 3, 4):47-102.

BLACKWELDER, R.E., 1945. Che cklist of the coleopterous insects of Mexico, Central America, the West Indies and South America. Bull. U.S. Nat. Mus. 185(3):343-550.

BLACKWELDER, R.E., 1957. Idem, ibidem, 185(6):V-VII, 927-1492.

CHE VROLAT, L.A.A. 1847. In d'Orbigny, Dict. Univ. Hist. Nat. 10:606.

CROTCH, G.R., 1851. List of Coccinellidae. 1-8, Cambridge.

CROTCH, G.R., 1873. Revision of the Coccinellidae of the United States. Trans. Am. Ent. Soc. 4: 363-382.

CROTCH, G.R., 1874. A Revision of the Coleopterous family Coccinellidae. E.W. Janson. London, $1-311$.

FABRICIUS, J.C., 1801. Systema eleutheratorum. 1:1-5, 6 Kiliae.

GORDON, R.D., 1985. North American Coccinellidae. J.N.Y. Ent. Soc. 93(1):851-862.

GORDON, R.D., 1987. A catalogue of the Crotch collection of Coccinellidae (Coleoptera). Occ. Pap. Syst. Ent. 25:16-17.

KORSCHEFSKY, R. 1932. Coleopterorum Catalogus. XVI(120), Coccinellidae II:565-570. W. Junk. Berlin.

LIMA, A.M., 1937. Espécies de Psyllobora. (Col. Coccinellidae). Mem. Inst. Oswaldo Cruz. 32:1-12, 2 figs. 3 est.

MULSANT, E., 1866-67. Monographie des Coccinellides. M. Savy. Lyon. 1-290. (Mém. L'Acad. Imp. Lyon, 16, 1866-67).

WEISE, J., 1902. Coccinelliden aus Sudamerika III. Ot ent. Z. pp. 161-176. 